\title{
Renta extraordinaria e industrialización en el neodesarrollismo. Límites y alternativas. Argentina, 2003-2012.
}

Resumen: El proyecto neodesarrollista en Argentina enfrenta, en su consolidación a diez años de haber nacido, límites en sus objetivos. La industrialización muestra significativos problemas para consolidarse, luego del largo proceso neoliberal. Estas limitantes están ligadas a un proceso de valorización asociado a la generación y apropiación de renta extraordinaria. Buscamos analizar el lugar de la renta extraordinaria en el proceso de valorización de capital en Argentina desde 2003 y cómo su centralidad limita las posibilidades de re-industrialización, aun en el estrecho concepto neodesarrollista del mismo. Analizaremos cómo la articulación entre renta extraordinaria e industria es mediada por la trasnacionalización del capital. Presentaremos una discusión sobre la modalidad que asume esa industrialización trunca y cuáles son las alternativas. Este trabajo se llevará adelante a partir de la discusión crítica de la literatura existente, y la construcción de estadísticas relevantes a partir de fuentes secundarias.

Palabras claves: Neodesarrollismo. Desarrollo. Renta. Argentina. Industrialización.

\section{Extraordinary rent and industrialization in neodevelopmentalism. Limits and alternatives. Argentina, 2003-2012.}

\begin{abstract}
Neodevelopmentalist project in Argentina faces, as it consolidates, its objective limits. Industrialization shows significative problems to bolster after the long neoliberal process. These limitations are tied to a process of valorization associated with the generation and appropriation of extraordinary rent. We look forward to analyze the place of extraordinary rent in the process of capital valorization in Argentina since 2003, and how its centrality limits the possibilities of re-industrialization, even within its restricted conception within neodevelopmentalism. We'll analyze how articulation between extraordinary rent and industry is mediated by trasnationalization of capital. We'll present a discussion over the modality of this truncated industrialization and the alternatives to it. This work we'll be done through the critical discussion of the literature, and the construction of relevant statistics from secondary sources.
\end{abstract}

Keywords: Neodevelopmentalism. Development. Rent. Argentina. Industrialization.

Códigos JEL (4-5): O1; O14; O19; B5.

\footnotetext{
*Investigador Adjunto del CONICET, en el Centro de Investigaciones Geográficas, Instituto de Investigaciones em Humanidades y Ciencias Sociales, Universidad Nacional de La Plata Profesor Adjunto Ordinario, Departamento de Sociología, UNLP Miembro del Centro de Estudios para el Cambio Social. Doctor en Ciencias Sociales (UBA) / Doctor en Ciencias Economicas (Paris XIII/Nord) Correo electrónico: marianfeliz@ gmail.com Dirección postal: Av. 7 no. 1386 (entre 61 y plaza Rocha), depto B, La Plata (1900), Argentina. Teléfono: 54-221$15-585-7590$
} 


\section{Introducción}

La última década ha iniciado para América del Sur un proceso de cambios novedoso con grandes continuidades. El principal rasgo ha sido la consolidación de patrones de desarrollo neodesarrollistas vinculados a procesos de extracción de las riquezas naturales y apropiación de renta extraordinaria (neoextractivismo) bajo distintas modalidades. El caso argentino es paradigmático al respecto. En lo que sigue analizaremos las características generales del proceso en la región, marcando las contradicciones que la apropiación de renta extraordinaria plantea a las estrategias de industrialización periféricas neodesarrollistas. Luego analizaremos en particular el caso de la Argentina. Finalmente, plantearemos unas breves conclusiones críticas con algunas líneas para debatir las alternativas frente al neoextractivismo.

\section{Suramérica: Del neoliberalismo al neodesarrollismo.}

La región Sudamericana atravesó desde finales de los años noventa la crisis del proyecto político del neoliberalismo. El neoliberalismo fue/es un proyecto de clase con el objetivo de recuperar el poder social global por parte de las nuevas fracciones dominantes del gran capital trasnacionalizado. Tal crisis no significó su fracaso tout court en la región sino su éxito en reconducir las contradicciones del capitalismo periférico a través de una nueva modalidad de participación en la división internacional del trabajo.

En el conjunto de los países del subcontinente, las fuerzas políticas hegemónicas (las viejas que pudieron superar la crisis neoliberal o las nuevas que nacieron a través de ella) se encaminaron a una nueva modalidad de desarrollo que intenta resolver productivamente los conflictos inherentes a la reproducción del capital en la periferia. Por un lado, debieron recuperar al Estado como instrumento clave en la promoción del "desarrollo" y medio para canalizar los conflictos sociales de clase a través de un reformulado y genérico desarrollismo (Féliz, 2012). Por otra parte, buscaron una forma de aprovechar a su favor las transformaciones creadas a través del neoliberalismo (su principal triunfo como proyecto sociopolítico de clase) en la estructura del capital a escala glocal (global-local) y los cambios en la geopolítica global que proyectan un mayor multilateralismo donde los llamados BRICS (Brasil, Rusia, India, China y Sudáfrica) ocupan una novedosa posición como potencias sub-imperiales.

A grandes rasgos podemos afirmar que esos intentos de conducir los desarrollos sociopolíticos locales luego de la caída del neoliberalismo en la región, llevaron a tres clases de procesos nacionales diferenciados pero articulados, si bien contradictoriamente. Por un lado, 
encontramos aquellos países en los cuales fuerzas populares débiles y desarticuladas no pudieron forzar una crisis del sistema de dominación que pudiera desplazar la hegemonía del programa neoliberal. En este campo se encuentran las experiencias de Colombia, Perú y Chile. En segundo lugar, están los países en los cuales las luchas sociales pudieron forzar una crisis abierta en el proyecto neoliberal pero las fuerzas populares fueron incapaces de desplazar del control político a las fracciones del capital que se habían convertido en hegemónicas a través del neoliberalismo. En estos casos, que incluyen a los países del Mercosur original (el "Bloque Atlántico" integrado por Brasil, Argentina, Uruguay y, hasta recientemente, Paraguay), la crisis del neoliberalismo se consumó bajo la forma de una superación del mismo en clave de proyecto de recomposición capitalista bajo el dominio del capital trasnacionalizado. Por último, Venezuela, Bolivia y Ecuador atravesaron la crisis del neoliberalismo con una reconfiguración radical de la hegemonía política. En estos países, las fuerzas populares irrumpieron en el sistema estatal, desplazando a las fuerzas políticas socialmente hegemónicas y abriendo el camino para proyectos de desarrollo ya no de recomposición capitalista sino de potencial transición a formas novedosas de organización social (Socialismo del Siglo XXI, Vivir Bien o Buen Vivir, Sumak Kawsay).

Con la excepción del primer grupo, en los distintos países de la región nos encontramos con formas nuevas de articulación del proceso de desarrollo con las consecuencias estructurales del neoliberalismo. El neoliberalismo legó a la región un espacio en el mercado mundial como fuente de tierra fértil, alimentos, minerales e hidrocarburos. Los nuevos Estados desarrollistas buscan canalizar efectivamente la nueva posición de las distintas naciones como proveedoras de riquezas naturales. La combinación de nuevo Estado desarrollista con esta renovada posición de oferente mundial de materias primas compone la clave estructural de lo que hemos denominado neodesarrollismo (Féliz y López, 2012; Féliz, 2012).

Estos proyectos neodesarrollistas buscan superar la histórica contradicción existente entre la industrialización periférica y una persistente inserción primarizada en la economía mundial. Desde los organismos internacionales (como la CEPAL) se plantea que estos países enfrentan la necesidad de superar el histórico paradigma desarrollista del "desarrollo hacia adentro" ahora reemplazado por un nuevo esquema conceptual: "el desarrollo desde dentro" (Sunkel, 1991). Siguiendo el ejemplo de los 'casos exitosos' del sudeste asiático, la industrialización por sustitución de importaciones (ISI) con el objetivo de satisfacción de las necesidades de consumo y producción locales debiera ser reemplazada por una estrategia de desarrollo del mercado interno (industrialización más sustitución de importaciones) cuyo 
objetivo es crear la base adecuada para convertir al espacio nacional en plataforma de exportación de materias primas y productos industriales de medio-bajo nivel de manufactura.

De esa manera, el nuevo desarrollismo pretende recuperar un programa articulado en torno al desarrollo industrial, pensado como núcleo de un proyecto nacional de desarrollo. En los países del eje del Buen Vivir, la industrialización es vista como un componente elemental del proyecto transicional que busca crear capacidades productivas y técnicas que permitan avanzar en la satisfacción de las necesidades populares. En estos países, el desarrollismo busca ser radicalizado apuntando a superar sus límites dialécticamente, trascendiendo su impronta capitalista periférica. Los países del Bloque Atlántico, por otra parte, ven a la industrialización como elemento de la estrategia de desarrollo capitalista con estabilidad política (basada en la “inclusión social” por la vía del empleo). En esa estrategia, la industrialización debe cumplir los requisitos de la competitividad internacional $\mathrm{y}$, a tal efecto, debe integrarse con la estructura productiva primarizada. En estos casos, la radicalización del desarrollismo no es más que su reproducción a escala ampliada, no su superación dialéctica.

\section{Renta extraordinaria e industrialización periférica.}

Los proyectos neodesarrollistas (en sus diversas vertientes) buscan resolver productivamente el dilema provocado por el peso de la producción primaria para la exportación y su consecuencia inmediata, la llamada "maldición de los recursos naturales". Este problema surge porque la abundancia de riquezas naturales a bajos costos de extracción -convertidas en recursos naturales a través de su mercantilización- provoca la aparición de una rentabilidad extraordinaria al momento de su exportación. Esa rentabilidad excedente en la producción primaria tiende a desviar recursos de inversión desde las actividades industriales que en general sólo obtienen una rentabilidad promedio ${ }^{1}$. Asimismo, la alta competitividad (bajos costos / alta rentabilidad) de la producción primaria para la exportación genera un ingreso excesivo de divisas internacionales, lo cual presiona sobre el tipo de cambio, abaratándolo y desprotegiendo a la industria manufacturera.

La renta extraordinaria no es producto de una particular habilidad de los productores sino de la particular facilidad para la extracción de las riquezas en un territorio determinado en comparación con el resto de los productores mundiales y dadas las condiciones de demanda

\footnotetext{
${ }^{1}$ En realidad, en la periferia, la condición productivamente "atrasada" del capital conduce al capital manufacturero a obtener rentabilidades generalmente menores a las medias de cada rama a escala global.
} 
global $^{2}$. La renta extraordinaria surge de la posibilidad de producir a costos excepcionalmente bajos para vender en el mercado mundial a los precios que garantizan un volumen de producción que satisfaga la demanda mundial. En un momento determinado, dada la demanda global de un recurso en particular (por ejemplo, petróleo) comenzarán a producir los productores que se encuentren en las regiones con mayor facilidad de extracción y por lo tanto con menores costos absolutos (ej., países petroleros: Arabia Saudita, Venezuela, etc.); el precio de producción garantizará una rentabilidad suficiente para esos productores. En la medida en que la demanda global continúa aumentando, el precio de producción se eleva para permitir que nuevos productores, con costos más elevados (ej., países con petróleo: Argentina, Brasil, etc.), puedan ingresar al mercado para satisfacer esa demanda adicional con rentabilidades normales. En estas condiciones, los productores de los países petroleros comenzarán a recibir una renta extraordinaria.

Cuando la demanda mundial de productos primarios se eleva (en las últimas décadas, básicamente por la irrupción de China e India en el mercado mundial capitalista), esos precios aumentan pues se incorporan nuevos productores con costos mayores para satisfacer la demanda excedente. Los mayores precios se traducen en un incremento en la rentabilidad en aquellos productores que tienen acceso a los recursos naturales en condiciones de costos de producción excepcionalmente bajos.

Los últimos lustros han sido para la región una etapa de apropiación excepcional de renta extraordinaria. Eso se expresa en la notable acumulación de reservas internacionales por parte del conjunto de los Bancos Centrales de los países de la región y, paralelamente, en un sostenido superávit en el balance comercial (CEPAL, 2012). Este es el resultado conjunto de un salto en los términos del intercambio (precios de las exportaciones de la región versus precios de las importaciones de productos extra-regionales) y una profundización del saqueo de la naturaleza para la producción primaria.

La existencia de condiciones productivas para la generación de renta extraordinaria involucra la prevalencia de lo que Diamand (1972) ha denominado Estructura Productiva Desequilibrada (EPD). Esto significa que en cada país los capitales en las ramas capaces de apropiar renta extraordinaria son mucho más rentables que aquellos que operan en el resto de las ramas de la producción y en particular mucho más rentables que el conjunto de los capitales que actúan en la industria manufacturera. Debido a que en el marco de las sociedades dominadas

\footnotetext{
2 Quienes se apropian de renta extraordinaria lo hacen por tener la propiedad privativa sobre el uso y extracción del recurso en cuestión.
} 
por el capital el tipo de cambio real es determinado por la competencia intercapitalista (Féliz, 2009), la existencia de volúmenes significativos de renta extraordinaria tiende a presionarlo hacia abajo. El desplazamiento de recursos productivos (plusvalor) de la industria poco rentable a la producción primaria (apropiadora de renta excedente) y el ingreso extraordinario de moneda internacional genera una presión que tiende a reducir el tipo de cambio real, es decir abaratar el dólar y/o incrementar los precios locales en moneda internacional. El resultado es que los capitales industriales locales que compiten con los foráneos (en tanto exportadores o importadores) ven caer su rentabilidad y, por lo tanto, ven reducida su capacidad de persistir como capitales. En la región surámericana (ubicada en el límite inferior de la semi-periferia global) el desarrollo de las fuerzas productivas es relativamente bajo, de forma tal que las ramas industriales utilizan el tipo de cambio como medio de protección y creación de competitividad (capacidad de valorizarse y acumular en el mercado mundial). Complementariamente, las empresas locales poco competitivas recurren a la precarización del empleo como instrumento de competencia y valorización compensatorio (Marini, 2007; Féliz y Chena, 2005).

En definitiva, la existencia de amplias ramas de producción capaces de apropiar renta extraordinaria contradicen el objetivo de industrializar explícitamente propuesto por el neodesarrollismo. La experiencia del proyecto neodesarrollista argentino da cuenta de lo flagrante de la misma, llevando a un extremo la contradicción entre las posibilidades del desarrollo capitalista en un país periférico y los límites impuestos específicamente por la expansión de las ramas rentistas con la promoción y protección por parte del Estado.

\section{Argentina: límites al proyecto de desarrollo capitalista periférico en la era de la trasnacionalización del capital.}

La Argentina atraviesa desde mediados de 2002 una modalidad específica de proyecto neodesarrollista (Féliz y López, 2012). Abandonando el neoliberalismo en una tromba, a través de una crisis orgánica (Gramsci, 2004), la recomposición progresiva de la legitimidad y hegemonía del capital se apoyó en una re-articulación de las políticas macroeconómicas, laborales y sociales (Féliz y Pérez, 2007; Féliz y López, 2012). Las mismas debieron simultáneamente crear condiciones para la valorización y acumulación de capital y un marco político capaz de recuperar la legitimidad de las formas sociales capitalistas y de desactivar la protesta social (Féliz, 2007). El proyecto de desarrollo capitalista que en Argentina fue estructurándose como neodesarrollista ha buscado resolver la contradicción señalada entre el 
peso estructural de la producción primaria exportadora y la propuesta de reimpulsar un proceso de desarrollo industrial periférico.

Los años del neoliberalismo permitieron impulsar en Argentina una nueva estrategia de inserción internacional. Las transformaciones en el conjunto del capital a escala global reubicaron al país como una plataforma exportadora de mercancías agropecuarias y minerales. A través de 30 años de neoliberalismo y con más ímpetu a partir de los años noventa, se produjo una profunda transformación en la producción agropecuaria que condujo al desarrollo sin par de la agricultura transgénica y en particular de la soja y sus manufacturas derivadas (grano, harinas, aceites). De ser un "yuyo" de poca monta a comienzos de los años 90, el complejo sojero representa cerca de un quinto de las exportaciones totales del país y su producción concentra más de la mitad del suelo fértil disponible para la producción agrícola (Vértiz, 2012). Este proceso fue acompañado de un salto significativo en la producción y productividad de otras mercancías agropecuarias (trigo, maíz, etc.). Esta transformación se produjo con el apoyo y promoción desde el Estado que autorizó sucesivamente la utilización de las nuevas semillas, fertilizantes y modalidades productivas (Svampa, 2011). Estos cambios condujeron a un profundo cambio en la producción agropecuaria (Basualdo, 2006), la cual pasó de estar controlada por tradicionales terratenientes locales propietarios de grandes parcelas de tierra a ser hegemonizada por grandes capitales trasnacionales, mayormente arrendatarios de tierras ajenas y organizados como capital financiero (los llamados pooles de siembra). En paralelo, de la mano de la promoción estatal se extendió a lo largo del territorio argentino una nueva modalidad de la minería (Svampa y Sola Álvarez, 2010). Bajo el control de grandes empresas transnacionales, la mega-minería a cielo abierto se abrió paso fundamentalmente a lo largo de la cordillera argentina. La reforma constitucional de 1994, que transfirió a las provincias el control de las riquezas naturales del subsuelo, creó el espacio jurídico para impulsar la transformación de la Argentina en una prometedora potencia minera, en particular en la minería del oro.

Si bien el nacimiento y desarrollo de ambos procesos se inició en la era neoliberal, el neodesarrollismo ha contribuido a su consolidación. Desde 2003 en adelante, tanto la producción de soja y minerales (en particular, oro) se conformaron en algunos de las principales fuentes de divisas internacionales y renta extraordinaria, pues prácticamente la totalidad de lo producido se destina al comercio exterior. Esta transformación estructural a nivel productivo junto con cambio en el nivel global en el precio de las mercancías poco diferenciadas 
(normalmente conocidas como "commodities") han conducido a que durante la última década la renta extraordinaria se transforme en un influjo sustancial de plusvalor (Iñigo Carrera, 2007).

En ese marco se impulsó un proceso denominado como de re-industrialización. Como señalamos, el neodesarrollismo pretende reforzar el crecimiento económico sobre la base de la acumulación de capital en las ramas de la industria manufacturera. Sin embargo, tal proceso debe enfrentarse a las limitaciones que impone la prevalencia de las ramas rentistas de la economía. En efecto, la recuperación económica iniciada a mediados de 2002 es acompañada por un crecimiento de la producción industrial. Partiendo de una bajísima utilización de la capacidad instalada y de insignificantes niveles de inversión bruta, el salto en la tasa de ganancia para el conjunto del gran capital y la reconfiguración de la demanda agregada a favor de las exportaciones y el consumo suntuario permitieron expandir la producción en todas las ramas (Féliz y López, 2012). En la medida en que aumentaba el uso de la capacidad productiva disponible y crecía el empleo de fuerza de trabajo asalariada, comenzaba un proceso de aumento en la inversión en medios de producción: la tasa de inversión subió de 12\% del PBI en 2002 a 22,6\% en 2011, ubicándose por encima de los promedios de los años de bonanza de la década anterior. La producción industrial pasó de representar el 15,4\% del PBI real en 2002 llegando a 16,3\% en 2011. Por un lado, la inversión aumenta pero menos que proporcionalmente con el salto en la rentabilidad del capital. Por otra parte, la recuperación en el peso de la industria en la generación de valor no le permite alcanzar el peso histórico de la industria en el PBI. En 1998 el PBI industrial representó el 17,2\% del PBI total.

El neodesarrollismo intenta articular en el mismo proceso de desarrollo a la industrialización y el neoextractivismo (Féliz, 2012). A tal efecto, desde el Estado se ha ido delineando una estrategia que se ha consolidado en el Plan Estratégico Industrial 2020 (PEI2020) que pretende expresar la unidad orgánica que se busca establecer entre las tradicionales actividades extractivistas (históricamente enfrentadas al proyecto desarrollista) y el núcleo de la industria manufacturera: "el concepto de industria debe tomarse como definición amplia ... Esta concepción deja de lado falsas antinomias, como la de 'campo' vs. 'industria', para focalizarse en el concepto de agregación de valor, de modo que a la dicotomía mencionada se la supere incorporando más industrialización a la actividad primaria” (Ministerio de Industria, 2011: 29). Esto aparece como una novedad en la estrategia de los sectores dominantes pues por primera vez producción extractiva y producción industrial buscan ser incluidas en un proyecto integral de desarrollo capitalista. 
Esta nueva forma de integración se expresa en el creciente peso de las actividades mineras y las manufacturas de productos primarios en el valor agregado de producción entre las grandes empresas.

Cuadro 1. Distribución del valor agregado, cúpula empresarial. Argentina, 19932009.

\begin{tabular}{|c|c|c|c|c|c|c|}
\hline Sector & 1993 & 1998 & 2003 & 2009 & $\begin{array}{c}2003- \\
2009\end{array}$ & $\begin{array}{l}1998- \\
2009\end{array}$ \\
\hline Minas y canteras & $8,0 \%$ & $8,0 \%$ & $\begin{array}{c}24,4 \\
\%\end{array}$ & $\begin{array}{c}19,0 \\
\%\end{array}$ & $-5,4 \%$ & $11,0 \%$ \\
\hline Industria manufacturera & $53,4 \%$ & $\begin{array}{c}48,6 \\
\%\end{array}$ & $\begin{array}{c}49,1 \\
\%\end{array}$ & $\begin{array}{c}48,8 \\
\%\end{array}$ & $-0,4 \%$ & $0,2 \%$ \\
\hline Alimentos, bebidas y tabaco & $18,5 \%$ & $\begin{array}{c}14,8 \\
\%\end{array}$ & $\begin{array}{c}18,1 \\
\%\end{array}$ & $\begin{array}{c}20,9 \\
\%\end{array}$ & $2,8 \%$ & $6,1 \%$ \\
\hline $\begin{array}{l}\text { Combustibles, químicos } \quad \mathrm{y} \\
\text { plásticos }\end{array}$ & $18,4 \%$ & $\begin{array}{c}19,3 \\
\%\end{array}$ & $\begin{array}{c}20,1 \\
\%\end{array}$ & $\begin{array}{c}16,8 \\
\%\end{array}$ & $-3,3 \%$ & $-2,5 \%$ \\
\hline Maquinarias, equipos y vehículos & $7,5 \%$ & $5,9 \%$ & $2,1 \%$ & $3,9 \%$ & $1,8 \%$ & $-2,0 \%$ \\
\hline Resto industria & $9,0 \%$ & $8,6 \%$ & $8,8 \%$ & $7,1 \%$ & $-1,7 \%$ & $-1,5 \%$ \\
\hline Electricidad, gas y agua & $10,1 \%$ & $9,3 \%$ & $5,8 \%$ & $5,1 \%$ & $-0,6 \%$ & $-4,2 \%$ \\
\hline Comunicaciones & $12,0 \%$ & $\begin{array}{c}15,7 \\
\%\end{array}$ & $8,6 \%$ & $\begin{array}{c}11,1 \\
\%\end{array}$ & $2,5 \%$ & $-4,6 \%$ \\
\hline Resto actividades & $16,6 \%$ & $\begin{array}{c}18,4 \\
\%\end{array}$ & $\begin{array}{c}12,1 \\
\%\end{array}$ & $\begin{array}{c}16,0 \\
\%\end{array}$ & $3,9 \%$ & $-2,4 \%$ \\
\hline
\end{tabular}

Fuente: Elaboración propia en base a datos de la Encuesta Nacional a Grandes Empresas del INDEC. Notas: Participación del valor agregado de las empresas de cada rama en el valor agregado total de la muestra.

El salto estructural del peso de la explotación minera y el crecimiento del sector productor de manufacturas de alimentos, bebidas y tabaco son una clara manifestación de esta tendencia.

Esta modalidad de desarrollo de la industria replica de manera novedosa la inserción periférica y dependiente del capitalismo argentino. La expansión del comercio exterior en manufacturas en la última década se ha apoyado sobre un puñado de manufacturas de origen agropecuario (MOA, fundamentalmente, aceite y harina de soja) y manufacturas de origen industrial (MOI) tales como metales preciosos (en particular, oro), agrocombustibles ("biodisel”) y automóviles (esto último, vinculado al régimen especial existente con Brasil) (cuadro 2). 
Cuadro 2. Exportaciones, peso relativo de los principales rubros. Argentina, 20032011.

\begin{tabular}{lccc}
\hline \hline \multicolumn{1}{c}{ Rubros } & $\begin{array}{c}\text { Participación en el } \\
\text { total, 2011 }\end{array}$ & Gran Rubro & $\begin{array}{c}\text { Var. } \\
2003- \\
2011\end{array}$ \\
\hline Cereales & $10,0 \%$ & Primarios & $2,3 \mathrm{pp}$ \\
Semillas y frutos oleaginosos & $7,1 \%$ & Primarios & $0,5 \mathrm{pp}$ \\
Carnes & $2,5 \%$ & MOA & $0,1 \mathrm{pp}$ \\
Grasas y aceites & $8,4 \%$ & MOA & $-1,1 \mathrm{pp}$ \\
$\begin{array}{l}\text { Residuos y desperdicios de la industria } \\
\text { alimenticia }\end{array}$ & $12,8 \%$ & MOA & $1,1 \mathrm{pp}$ \\
$\begin{array}{l}\text { Productos químicos y conexos } \\
\text { Piedras y metales preciosos }\end{array}$ & $7,0 \%$ & MOI & $1,7 \mathrm{pp}$ \\
Metales comunes y sus manufacturas & $3,3 \%$ & MOI & $2,9 \mathrm{pp}$ \\
$\begin{array}{l}\text { Máquinas, aparatos y materiales } \\
\text { eléctricos }\end{array}$ & $3,6 \%$ & MOI & $-1,5 \mathrm{pp}$ \\
$\begin{array}{l}\text { Material de transporte terrestre } \\
\text { Petróleo crudo }\end{array}$ & $2,9 \%$ & MOI & $0 \mathrm{pp}$ \\
$\begin{array}{l}\text { Carburantes, grasas y } \\
\text { lubricantes }\end{array}$ & $11,9 \%$ & MOI & $7,1 \mathrm{pp}$ \\
\hline \hline
\end{tabular}

Fuente: Elaboración propia en base a datos del INDEC. Notas: pp: puntos porcentuales.

Es significativo que por fuera de las exportaciones de automóviles -destinadas preferentemente al Brasil en el marco de un régimen especial de promoción-, las ventas externas de alimentos y bebidas, y las exportaciones de metales comunes, las manufacturas industriales han tenido una pobre performance en relación al comercio exterior (cuadro 3 ). ${ }^{3}$

\footnotetext{
${ }^{3}$ Podríamos sostener que el sector automotriz actúa como sector rentista dentro del conjunto de la industria. Los capitales que allí se reproducen aprovechan las ventajas extraordinarias (y la rentabilidad extraordinaria) generadas por el régimen especial creado en el marco del Mercosur.
} 
Cuadro 3. Exportaciones industriales. Millones de dólares corrientes. Argentina, 1998, 2003, 2010.

\begin{tabular}{|c|c|c|c|c|c|c|}
\hline & & & 1998 & 2003 & 2010 & $\begin{array}{l}2003- \\
2010\end{array}$ \\
\hline Alimentos y bebidas & & & $8.172,1$ & $9.295,4$ & $21.461,5$ & $131 \%$ \\
\hline Metales comunes & & & $1.095,8$ & $1.522,8$ & $4.465,8$ & $193 \%$ \\
\hline $\begin{array}{l}\text { Vehículos automotores, } \\
\text { semiremolques }\end{array}$ & remolques & $\mathrm{y}$ & $3.236,9$ & $1.563,6$ & $8.177,9$ & $423 \%$ \\
\hline Resto & & & $6.096,2$ & $8.551,0$ & $15.187,9$ & $78 \%$ \\
\hline Total & & & $18.600,9$ & $20.932,8$ & $49.293,1$ & $135 \%$ \\
\hline
\end{tabular}

Fuente: Elaboración propia sobre la base de datos del INDEC.

El PEI2020 pretende mostrarse como un sólido programa para el desarrollo "sustentable" (o “con inclusión") a través de la reindustrialización. Es una buena síntesis de los intereses de los sectores que hegemonizan la acumulación de capital en Argentina luego del neoliberalismo. En efecto, más allá de las orientaciones generales, el Plan presenta los "consensos" básicos que orientan -y orientarán en el futuro- el programa de reindustrialización. Sin embargo, surgen algunas dudas en cuanto a la realidad de algunas de las proyecciones y especialmente- a los objetivos mismos que presenta como deseables. En lo que sigue analizaremos brevemente las barreras del proyecto industrializador dentro del neodesarrollismo y sus límites más allá de él en un país periférico y dependiente.

Primero que todo, el proyecto neodesarrollista plasmado en el PEI2020 recoge la propuesta esbozada por Sunkel (1991) sobre la necesidad de pasar del desarrollo "hacia adentro" al desarrollo "desde adentro". Enfatiza claramente la necesidad de "dar un salto exportador" (Ministerio de Industria, 2011: 275) pero niega la contradicción entre el desarrollo del mercado interno y el "estímulo" a la inversión privada (Ministerio de Industria, 2011: 272). $\mathrm{Al}$ respecto cabe señalar que el aumento en la tasa de inversión (que debería pasar de 22,6\% alcanzado en 2011 a 28\% para mantener un crecimiento sostenido superior al 5\%; Ministerio de Industria, 2011: 35) supone en un marco expansivo una reducción sistemática del peso relativo del ingreso de los trabajadores, al menos hasta que la inversión alcance un nuevo nivel ${ }^{4}$. De allí en más, las demandas de los trabajadores deberán restringirse al aumento en la

\footnotetext{
${ }^{4}$ Por supuesto, en un marco menos expansivo (como el que potencialmente resultaría de la profundización de la crisis en el capitalismo en el centro) la presión para contener los salarios a los fines de expandir la inversión sería proporcionalmente mayor, propiciando una reducción absoluta en los ingresos de -al menos- una fracción de la fuerza de trabajo.
} 
productividad laboral (Curia, 2007). La pregunta es porque el conjunto de los trabajadores debieran conformarse con una fracción relativamente menor del ingreso total cuando el consumo suntuario y las inversiones quedan en mano de un puñado de hombres y mujeres: la clase capitalista apropia al menos el 18\% del ingreso registrado en la Encuesta Permanente de Hogares (Pérez y Barrera, 2012), realiza casi el 60\% del consumo total (Féliz, 2008) y controla la casi totalidad de las inversiones.

Por otra parte, cabe preguntarse por la necesidad de orientar el desarrollo en torno a la búsqueda de competitividad exportadora. La competividad es un concepto estrictamente relativo y vinculado a las formas capitalistas de desarrollo. Es un concepto que remite a la necesidad -devenida objetiva por las relaciones sociales de producción- de competir permanentemente, de aumentar sistemáticamente la productividad y de ganar espacios en el mercado. La competitividad se convierte en un fin en sí mismo e implica articular la política económica alrededor de la presión permanente sobre las condiciones de vida y de trabajo (Féliz, 2009b). Desde el punto de vista de sus manifestaciones, la competitividad se refleja en la evolución del tipo de cambio real tendencial (TCRT) que da cuenta de la evolución relativa de los costos laborales unitarios reales (CLUR) (Féliz, 2009, 2011). A este respecto, la experiencia de industrialización neodesarrollista en Argentina no es auspiciosa pues la tendencia del tipo de cambio real ha sido a una sistemática apreciación desde los primero años de la etapa actual (Féliz, 2009). Esa apreciación ha sido el resultado de un pobre desempeño de la productividad de la industria manufacturera en contraste con el capital manufacturero en el resto del mundo (Féliz, 2011).

Esta evidencia lleva al tercer punto clave: ¿por qué a pesar de la elevada rentabilidad global del capital local, la tasa de inversión se mantiene relativamente baja y por lo tanto la productividad no crece lo suficiente?. En efecto, al tiempo que la rentabilidad del gran capital local se ha incrementado un $40 \%$ en la década frente a la década de los noventa (Féliz y López, 2012), su tasa de inversión se ha reducido fuertemente (Manzanelli, 2011): sólo 1 de cada 5 pesos de excedente son reinvertidos. Este proceso se vincula a al menos dos fenómenos estructurales que la política neoindustrialista no ha considerado en profundidad. Por un lado, el peso del fenómeno de la renta extraordinaria hace innecesario para el capital la reinversión de una porción importante del plusvalor. Dado que la renta excedente resulta de las condiciones excepcionales de acceso y/o producción de alguna mercancía, la reproducción de la misma requiere sólo la reinversión de una fracción menor del ingreso extraordinario apropiado. Aumentar la tasa de inversión en las condiciones tecnológicas corrientes no permite aumentar 
significativamente la rentabilidad "normal" y por ello los capitales sólo reinvierten el monto necesario para garantizar las condiciones medias de operación de los emprendimientos que en esas condiciones siguen generando renta extraordinaria. De allí que una parte importante del plusvalor apropiado se oriente a otros usos improductivos y, en particular, a otros espacios de valor. En segundo lugar, la preeminencia del gran capital trasnacionalizado en la economía limita la autonomía material del ciclo del capital local (Marini, 1979). La orientación global de las corporaciones las lleva a privilegiar su estrategia de expansión a escala internacional, derivando el plusvalor creado en cualquier espacio de valor e invirtiéndolo donde sea más conveniente en función de esa estrategia. En particular, en el último lustro la profundización de la crisis en el capitalismo en el centro, ha llevado a muchas trasnacionales a desviar una fracción importante de su rentabilidad hacia las casas matrices para compensar las pérdidas generadas allí y financiar su reestructuración.

Estos elementos abren serias dudas sobre la realidad de un proyecto de industrialización progresivo en Argentina en el marco de un proyecto de consolidación de una formación capitalista periférica. Las barreras mencionadas señalan que tal proyecto enfrenta límites muy concretos que bloquean las posibilidades de redistribución de ingresos e inclusión social extendida. Algunas estimaciones muestran que la participación de los salarios en el ingreso se ha estancado con una leve tendencia a retroceder desde 2008 (Fernández y González, 2012: 21) y la pobreza por ingreso superaría el 30\% de la población (Lozano, 2012).

Amen de esos límites, cabe agregar otras apreciaciones sobre los presupuestos y objetivos del proyecto neodesarrollista y que suponen superar la crítica interna del desarrollo capitalista periférico. Por una parte, el proyecto explicitado en el PEI2020 asume el crecimiento sin límites como el origen y objetivo de todo programa de desarrollo. Mientras se está abriendo un renovado debate sobre los costos sociales y ambientales del "progreso" (Svampa y Sola Álvarez, 2010), el neodesarrollismo argentino sugiere que el mismo se asocia simplemente a la expansión de la base material de la producción. Brilla por su ausencia cualquier consideración sobre las implicancias de la multiplicación del actual patrón de consumo tanto en términos de calidad de la vida en sociedad como en términos de sus costos socioambientales. Segundo, bajo el velo de un proyecto de autonomía nacional, el proyecto de las clases dominantes apunta a consolidar un patrón de producción de la sociedad que emule la experiencia de los países capitalistas centrales. Se asume la deseabilidad de tal "estilo de desarrollo", parafraseando a Pinto (1976), sin siquiera poner a debate la conveniencia del mismo o siquiera la factibilidad en el contexto de la sociedad argentina contemporánea. 
En cuanto al sujeto del cambio, la propuesta del PEI2020 es clara en cuanto a poner a la burguesía local como agente motor. Será ella la que orientará el desarrollo a través de sus decisiones de inversión, auspiciadas y orientadas por las políticas estatales. Lo que no parece claro en el PEI2020 es el gran peso del gran capital trasnacionalizado a la hora de construir una estrategia de desarrollo -siquiera capitalista periférica- con cierta autonomía. Se presenta el PEI2020 como un plan construido sobre la base del consenso en los actores relevantes, pero el peso superlativo del capital más concentrado en esos debates pone en duda el grado de autonomía política en la definición de orientaciones y políticas.

En síntesis, el proyecto neodesarrollista y sus expectativas de industrialización enfrentan serias barreras. Más allá del optimismo implícito en el PEI2020, que refleja la hegemonía consolidada de los sectores trasnacionalizados del gran capital, el proyecto de industrialización en la periferia capitalista presenta límites históricos difíciles de resolver. Frente a esta situación, la pregunta que en el fondo debe plantearse un proyecto de desarrollo en Argentina tiene dos partes. Primero, ¿si la periferia necesita llevar adelante un proceso de industrialización, qué características debiera tener para servir de transición a las restricciones para el desarrollo en el marco del capitalismo periférico en suramérica? Segundo, ¿es necesario un proceso de industrialización periférico o se requiere repensar el desarrollo superando el mito industrialista?

\section{Reflexiones preliminares ¿Es posible salir de la trampa de la renta extraordinaria?}

Como hemos visto, la existencia de fuentes de rentas extraordinarias genera una situación compleja y contradictoria. El caso de la Argentina en la última década es ilustrativo al respecto. Por un lado, la nueva base productiva construida a través del neoliberalismo busca con cierto éxito aprovechar el desarrollo de formas expoliadoras de explotación de las riquezas naturales, para hacer uso de la renta excedente en proyectos de desarrollo que garanticen simultáneamente un cierto desarrollo industrial primarizado (bajo control del capital trasnacionalizado) junto a una redistribución social de una porción menor de esos recursos a los fines de la canalización socialmente productiva de la conflictividad. En los proyectos de transición radical de tendencia poscapitalista (el espacio ALBA), la irrupción del pueblo trabajador en el aparato estatal multiplica la orientación y volumen de la redistribución social de la renta. En los proyectos neodesarrollistas de reproducción ampliada del capitalismo (el "bloque atlántico") la renta es fundamentalmente utilizada para impulsar la expansión subsidiada del capital en el espacio de valor nacional periférico. En todos estos casos, la renta 
proveniente de la explotación y exportación de los recursos naturales se convierte en un flujo de valor de magnitud variable pero siempre políticamente importante.

Por otra parte, la prevalencia de la apropiación de renta extraordinaria como fenómeno macroeconómico contradice las posibilidades de avanzar en un proyecto de desarrollo donde la industria orientada a la satisfacción de las necesidades populares. En la Argentina, la producción de Soja para la exportación concentra espacios crecientes de tierra fértil y agua, restando estos valiosos recursos de la producción de alimentos para el consumo local. Además, la presión ejercida por la renta sojera en el precio de la tierra e insumos, aumenta el precio final del resto de las producciones agropecuarias competidoras. De alguna manera, podría decirse que el impacto de la renta extraordinaria se traslada desde el comercio exterior a todas las mercancías, transformándose a nivel interno en un mecanismo de redistribución de ingresos desde el pueblo trabajador al conjunto del capital. A su vez, la mega-minería a cielo abierto de base trasnacional concentra una creciente masa de recursos para su extracción y transporte a los puertos de exportación, convirtiéndose en ejemplos de la histórica economía de enclave con pocos encadenamientos productivos hacia atrás (proveedores e insumos) y especialmente hacia delante (en el uso industrial de los productos mineros).

Desmontar la trampa de los recursos naturales supone avanzar en varios frentes simultáneamente, la mayoría de los cuales están siendo discutidos desde los movimientos populares de la región y, en particular, en Argentina. Primero, avanzar en mecanismos de apropiación integral de la renta extraordinaria por parte del Estado, desprivatizando su utilización. Esto permitirá una utilización más racional socialmente, evitando su desvío hacia usos improductivos, la fuga de capitales y el consumo suntuario. En algunos de los países del eje del ALBA se ha avanzado en tal sentido. En Argentina, esto incluiría recuperar instrumentos de gestión del comercio internacional como el IAPI (Instituto Argentino de Promoción del Intercambio) y las Juntas Nacionales de Granos y Carnes que nacieron en los 40 y fueron abolidas definitivamente en los años noventa. Esto permitirá definitivamente aprovechar la existencia de condiciones locales favorables de producción de alimentos para la satisfacción del consumo popular a precios razonables. En segundo lugar, deben suspenderse las concesiones de las mega-mineras transnacionales, federalizando pero socializando la gestión de los recursos del subsuelo (quitándolos del control unilateral de las provincias) y comenzar a definir una estrategia de utilización de las riquezas mineras que contemple las necesidades de la Madre Tierra y su aprovechamiento sin expoliación para la satisfacción de las demandas populares. Tercero, debe avanzarse en un programa de reforma integral de la producción agropecuaria, 
que permita desplazar progresivamente la producción de Soja. Esto deberá incluir tanto mayor control sobre el uso de agrotóxicos, como el castigo impositivo a la producción de Soja y el incentivo al uso de formas cooperativas de gestión de la producción en el campo. Cuarto, reemplazar a las divisas provistas por la Soja supone fundamentalmente contener el uso indiscriminado de las mismas en consumo suntuario, insumos importados por las trasnacionales y la fuga a través de mecanismos impositivos y por la vía de la deuda externa.

La crisis del proyecto neoliberal ha abierto en América del Sur una ventana de oportunidad. Los pueblos de la región avanzan en una crítica a sus consecuencias estructurales. Esto supone la puesta en discusión de las formas del desarrollo capitalista en la periferia y requiere el cuestionamiento del lugar que ocupa el proceso de apropiación de renta extraordinaria y la expoliación de las riquezas naturales. Esto vale para los proceso más radicales de tendencia transicional (el espacio del ALBA) tanto como para los procesos de neodesarrollismo de reproducción ampliada del capital.

\section{Referencias bibliográficas}

Basualdo, Eduardo (2006). Estudios de historia económica argentina. Desde mediados del siglo XX a la actualidad. Buenos Aires, Siglo Veintiuno Editores.

CEPAL (2012). Balance preliminar de las economías de América Latina y el Caribe. Santiago de Chile.

Curia, Eduardo (2007). Teoría del modelo de desarrollo de la Argentina: las condiciones para su continuidad. Buenos Aires, Galerna.

Diamand, Marcelo (1972). La estructura productiva desequilibrada. Argentina y el tipo de cambio. Desarrollo Económico, 12(45). crossrefhttp://dx.doi.org/10.2307/3465991

Féliz, Mariano (2007). ¿Hacia el neodesarrollismo en Argentina? De la reestructuración capitalista a su estabilización. Anuario EDI, 3, 68-81, Ediciones Luxemburg.

Féliz, Mariano (2008). Los límites macroeconómicos del neo-desarrollismo. Herramienta. Revista de debate y crítica marxista, 39, 97-116.

Féliz, Mariano (2009). Crisis cambiaria en Argentina. Problemas del Desarrollo. Revista Latinoamericana de Economía, 40 (158), 185-213.

Féliz, Mariano (2009b). ¿No hay alternativa frente al ajuste? Crisis, competitividad y opciones populares en Argentina. Herramienta. Revista de debate y crítica marxista, Octubre, 42, 147160. 
Féliz, Mariano (2011). Un estudio sobre la crisis en un país periférico. La economía argentina del crecimiento a la crisis, 1991-2002. , Buenos Aires: Editorial El Colectivo.

Féliz, Mariano (2012). Sin clase. Neodesarrollismo y neoestructuralismo en Argentina (20022011). Século XXI: Revista de Ciências Sociais, 2(2), 9-43.

Féliz, Mariano \& Chena, Pablo (2005). Tendencias del mercado de trabajo en la economía periférica. Algunas tesis para el caso de Argentina. En: Neffa, Julio C. (coord.). Desequilibrios en el mercado de trabajo argentino. Los desafíos en la postconvertibilidad, CEILPIETTE/CONICET. Buenos Aires, Asociación Trabajo y Sociedad.

Féliz, Mariano \& López, Emiliano (2012). Proyecto neodesarrollista en Argentina ¿Modelo nacional-popular o nueva etapa en el desarrollo capitalista?. Buenos Aires: Editorial El Colectivo.

Féliz, Mariano \& Pérez, Pablo Ernesto (2007). ¿Tiempos de cambio? Contradicciones y conflictos en la política económica de la posconvertibilidad. En: Boyer, Robert \& Neffa, Julio C. (comp.). Salidas de crisis y estrategias alternativas de desarrollo. La experiencia argentina. Buenos Aires: Institut CDC pour la Recherche / CEIL-PIETTE/CONICET, Editorial Miño y Dávila.

Fernández, Ana L. \& González, Mariana L. (2012). Desigualdad en los ingresos laborales. Su evolución en la posconvertibilidad. Apuntes para el Cambio, 3.

Gramsci, A. (2004). Antología. México: Siglo XXI editores.

Iñigo Carrera, Juan (2007). La formación económica de la sociedad argentina. Volumen I: Renta agraria ganancia industrial y deuda externa. 1882-2004. Buenos Aires: Imago Mundi.

Lozano, Claudio (2012). Entrevista a Claudio Lozano. 'Que entre el 31 y el 40\% de la población esté bajo la línea de pobreza es un serio llamado de atención'. ACTA. La agencia de noticias de la CTA. Recuperado el 28 de Agosto de 2012 de http://www.agenciacta.org/spip.php?article5529.

Manzanelli, Pablo (2011). Peculiaridades en el comportamiento de la formación de capital en las grandes empresas durante la posconvertibilidad. Apuntes para el Cambio, 1.

Marini, Ruy Mauro (1979). El ciclo del capital en la economía dependiente. En: Oswald, Ursula (coord.). Mercado y dependencia. (pp. 37-55). México, Nueva Imagen.

Marini, Ruy Mauro (2007). Dialéctica de la dependencia (1973). En: Marini, R.M.. América Latina, dependencia y globalización. (pp. 99-137). Buenos Aires: CLACSO - Prometeo Libros.

Ministerio de Industria (2011). Plan Estratégico Industrial 2020. Recuperado el 13 de Agosto de 2012 de http://www.industria.gob.ar/planeamientoestrategico/wpcontent/uploads/2012/05/PEI\%2020\%2020\%20\%202012.pdf.

Pérez, Pablo Ernesto \& Barrera, Facundo (2012). Estructura de Clases, inserción laboral y desigualdad en la post-convertibilidad. En: Féliz, M. \& otros. Más allá del individuo. Clases 
sociales, transformaciones económicas y políticas estatales en la Argentina contemporánea. (pp.225-249). Buenos Aires: Editorial El Colectivo.

Pinto, Anibal (1976). Notas sobre estilos de desarrollo en América Latina. Revista de la CEPAL, 1 .

Sunkel, Osvaldo (1991). El desarrollo desde dentro. Un enfoque neoestructuralista para la América Latina. México: Fondo de Cultura Económica.

Svampa, Maristella \& Sola Álvarez, Marian (2010). Modelo minero, resistencias sociales y estilos de desarrollo: los marcos de la discusión en la Argentina. Ecuador Debate, 79.

Svampa, Maristella (2011). Extractivismo neodesarrollista, Gobiernos y Movimientos Sociales en América Latina. Revista Problèmes de l'Amérique Latine, 81, 103-128.

Vértiz, Francisco (2012). Apuntes sobre la producción agropecuaria para un proyecto emancipador. Debates Urgentes, 1(2), 67-105.

Recebido em 12.02.14

Aprovado em 19.09.14 